\title{
Verbal memory declines more in female patients with Parkinson's disease: the importance of gender- corrected normative data
}

\author{
S. Fengler ${ }^{1,2}$, S. Roeske ${ }^{3}$, I. Heber ${ }^{4}$, K. Reetz ${ }^{4,5}$, J. B. Schulz ${ }^{4,5}$, O. Riedel ${ }^{6}$, H.U. Wittchen ${ }^{7}$, A. Storch ${ }^{8}$, \\ K. Linse ${ }^{8}$, S. Baudrexel ${ }^{9}$, R. Hilker ${ }^{9}$, B. Mollenhauer ${ }^{10,11}$, K. Witt ${ }^{12}$, N. Schmidt ${ }^{12}$, \\ M. Balzer-Geldsetzer ${ }^{13}$, J. Dams ${ }^{13}$, R. Dodel ${ }^{13}$, S. Gräber ${ }^{14}$, A. Pilotto ${ }^{14}$, A. Petrelli ${ }^{2}$, S. Fünkele ${ }^{15}$, \\ J. Kassubek ${ }^{15}$ and E. Kalbe ${ }^{1,2 *}$ \\ ${ }^{1}$ Department of Medical Psychology, University Hospital Cologne, Germany; ${ }^{2}$ Institute of Gerontology \& Center for Neuropsychological Diagnostics \\ and Intervention (CeNDI), University of Vechta, Germany; ${ }^{3}$ Department of Neurology, University Hospital Bonn, and German Center for \\ Neurodegenerative Diseases (DZNE), Bonn, Germany; ${ }^{4}$ Department of Neurology, Medical Faculty, RWTH Aachen University, Germany; \\ ${ }^{5}$ JARA - Translational Brain Medicine, Jülich and Aachen, Germany; ${ }^{6}$ Leibniz-Institute of Prevention Research and Epidemiology, Department of \\ Clinical Epidemiology, Bremen, Germany; ${ }^{7}$ Institute of Clinical Psychology and Psychotherapy, Technische Universität Dresden, Germany; ${ }^{8}$ Division \\ of Neurodegenerative Diseases, Department of Neurology, Technische Universität Dresden, Germany; ${ }^{9}$ Department of Neurology, J.W. Goethe \\ University, Frankfurt/Main, Germany; ${ }^{10}$ Department of Neuropathology, University Medical Center Goettingen, Germany; ${ }^{11}$ Paracelsus-Elena \\ Clinic, Centre of Parkinsonism and Movement Disorders, Kassel, Germany; ${ }^{12}$ Department of Neurology, Christian Albrechts University, Kiel, \\ Germany; ${ }^{13}$ Department of Neurology, Philipps University Marburg, Germany; ${ }^{14}$ Department of Neurodegenerative Diseases, Hertie Institute for \\ Clinical Brain Research and German Center for Neurodegenerative Diseases (DZNE), University Tübingen, and German Center for \\ Neurodegenerative Diseases, Tübingen, Germany; ${ }^{15}$ Department of Neurology, University of Ulm, Germany
}

Background. Data on gender-specific profiles of cognitive functions in patients with Parkinson's disease (PD) are rare and inconsistent, and possible disease-confounding factors have been insufficiently considered.

Method. The LANDSCAPE study on cognition in PD enrolled 656 PD patients (267 without cognitive impairment, $66 \%$ male; 292 with mild cognitive impairment, 69\% male; 97 with PD dementia, 69\% male). Raw values and age-, education-, and gender-corrected $Z$ scores of a neuropsychological test battery (CERAD-Plus) were compared between genders. Motor symptoms, disease duration, L-dopa equivalent daily dose, depression - and additionally age and education for the raw value analysis - were taken as covariates.

Results. Raw-score analysis replicated results of previous studies in that female PD patients were superior in verbal memory (word list learning, $p=0.02$; recall, $p=0.03$ ), while men outperformed women in visuoconstruction $(p=0.002)$ and figural memory $(p=0.005)$. In contrast, gender-corrected $Z$ scores showed that men were superior in verbal memory (word list learning, $p=0.02$; recall, $p=0.02$; recognition, $p=0.04$ ), while no difference was found for visuospatial tests. This picture could be observed both in the overall analysis of PD patients as well as in a differentiated group analysis.

Conclusions. Normative data corrected for gender and other sociodemographic variables are relevant, since they may elucidate a markedly different cognitive profile compared to raw scores. Our study also suggests that verbal memory decline is stronger in women than in men with PD. Future studies are needed to replicate these findings, examine the progression of gender-specific cognitive decline in PD and define different underlying mechanisms of this dysfunction.

Received 24 October 2015; Revised 15 March 2016; Accepted 5 April 2016; First published online 19 May 2016

Key words: Cognition, gender, Parkinson's disease.

\section{Introduction}

Phenotypic heterogeneity in Parkinson's disease (PD) is being increasingly recognized (van Rooden et al. 2011). Recently, gender differences have attracted

* Address for correspondence: Prof. Dr. E. Kalbe, Department of Medical Psychology, University Hospital Cologne, Kerpener Str. 68, 50937 Cologne, Germany.

(Email: elke.kalbe@uk-koeln.de) interest as a potential contributing factor to this heterogeneity. For example, there is general agreement that both incidence and prevalence of PD are higher in men than in women (e.g. Van Den Eeden et al. 2003; de Lau et al. 2004; Taylor et al. 2007). Moreover, women are older at disease onset compared to men (Twelves et al. 2003). Furthermore, women may be more likely to exhibit the tremor-dominant PD phenotype (Haaxma et al. 2007) while motor symptoms other than tremor have been demonstrated to occur less 
frequently in women (Scott et al. 2000), with the exception of dyskinesias (Lyons et al. 1998).

Next to the core motor symptoms, non-motor symptoms of PD are receiving increasing attention for their important role in disability and reduction of quality of life. Here, cognitive impairment is one of the most common and relevant symptoms, with about $25 \%$ of PD patients being affected (Aarsland et al. 2010). Nevertheless, studies concerning gender differences in cognition have been scarce and inconsistent. While some studies did not find any effect of gender (Amick et al. 2006; Schendan et al. 2009; Crizzle et al. 2012), other reports indicate that differences exist. For example, lower global cognition scores in nondemented men with PD have been reported in studies using the Mini Mental State Examination (MMSE; Lyons et al. 1998; Hariz et al. 2003; Uc et al. 2009) and the Montreal Cognitive Assessment (MoCA; Nazem et al. 2009; Hu et al. 2014; Szewczyk-Krolikowski et al. 2014). Regarding specific domains, non-demented females with PD were found to be superior in both semantic and phonemic verbal fluency (Locascio et al. 2003; Szewczyk-Krolikowski et al. 2014). Furthermore, a result found both in studies comparing male and female PD patients (Riedel et al. 2008) and comparing PD patients with a healthy control group (Carey et al. 2002; Locascio et al. 2003) demonstrated that women with PD have poorer visuospatial abilities. In line with these findings, in the largest investigation so far that specifically examined this topic, Pasotti et al. (2012) tested 162 male and 144 female PD patients and reported that women with $\mathrm{PD}$ had significantly higher scores on a delayed verbal recall task, whereas men had better visuospatial abilities. Interestingly, these differences were dependent on disease duration: they were present in the early stage (disease duration $<6$ years), diminished in the intermediate stage (disease duration 6-10 years) and disappeared in the late stages of the disease (disease duration $>10$ years).

To date, two reviews have focused on the topic of gender differences in cognition in PD, one summarizing 11 studies (Miller \& Cronin-Golomb, 2010) and one recent review including eight studies (Heller et al. 2013). Consistent with the above-mentioned results, both studies summarized that differences in cognitive profiles between men and women exist, especially in verbal and visuospatial abilities. However, both reviews also came to the conclusion that the literature is far from conclusive. They suggest possible mediators, such as age, motor symptoms or medication, as well as other factors which may account for gender differences need to be taken into consideration in a more thorough way. Among these factors are conditions such as depression for which women are more vulnerable in general (Abate, 2013) and also specifically in PD (Riedel et al. 2010; Leentjens et al. 2013), and which can have a strong influence on cognitive functions. Importantly, both reviews also emphasize that it has to be clarified whether the observed effects are really PD specific or rather reflect a more general gender effect. It has to be taken into account that cognitive functions are also known to be different in healthy men and women (van Hooren et al. 2007; Munro et al. 2012), and that the described genderspecific profiles in PD patients so far resemble those in healthy adults: women are typically superior on tests of verbal learning and memory, whereas men perform better in the visuospatial domain (Munro et al. 2012).

Two alternative methods exist to control for genderrelated performance differences in healthy adults and thus separate 'regular' gender effects from a diseasespecific deterioration of functioning. One is to include a healthy control group and compare male and female PD patients to healthy men and women, respectively, and the other is to include only patients but to use gender-corrected normative data. Remarkably, only two of the studies described above (Carey et al. 2002; Locascio et al. 2003) included a control group and, even more striking, no study so far has used gendercorrected data. Indeed, using a control group permits an explicit definition of whether patients have dysfunction compared to sex-matched controls. However, with this procedure the difference between male PD patients and their healthy counterparts on the one hand and between female PD patients and healthy women on the other is not directly tested, so the extent of dysfunction in female compared to male PD patients is difficult to define.

In contrast, gender-corrected $Z$ scores enable us to quantitatively compare the disease-specific cognitive deficits between men and women, since the deviations of each gender from a matched control group can be compared directly by means of a standardized value. The major advantage of this approach is that the sample size of the healthy population from which normative data is derived in tests or test batteries is usually large, while the sample size of healthy control groups in specific studies is often comparably small. At the same time, all relevant parameters, such as age and education, can be controlled for - at least if a test battery is used, which provides corrections for these sociodemographic variables.

Another important point is whether potential gender differences in PD are dependent on the stage of cognitive dysfunction. In the healthy population, gender differences in cognition have been shown to be relatively persistent (de Frias et al. 2006). In contrast, as described above, Pasotti et al. (2012) found that gender differences disappeared with increasing disease duration. 
As their analysis did not control for the differences in the normal population, it has to be investigated whether the same development is evident if differences in healthy adults are taken into account, e.g. by using gender-corrected normative scores.

In summary, only a few, inconclusive results regarding gender-specific profiles of cognitive (dys-)function in PD exist, and possible disease-confounding factors are insufficiently considered. Thus, the aim of the current study was to define gender-related cognitive profiles in PD (above and beyond gender differences in healthy adults) in a large and well-defined cohort of patients taken from the LANDSCAPE study (Balzer-Geldsetzer et al. 2011) including patients with different levels of cognitive functions, i.e. with no cognitive impairment (PD-N), with mild cognitive impairment (PD-MCI), and PD dementia (PD-D). Hereby we controlled for the most important possible influencing factors of age, education, severity of motor symptoms, disease duration, depression and L-dopa equivalent daily dose.

We hypothesized that our raw-value analysis would replicate previous gender-specific profiles, both from studies of healthy individuals and from PD studies, which have usually been based on analysis of raw scores. More specifically, we expected superior verbal memory and verbal fluency performance but inferior visuospatial abilities in female compared to male PD patients - a profile that should be most evident in patients with no or early cognitive deficits, but that should become less pronounced with more severe cognitive dysfunction. Furthermore, based on the findings discussed above that differences regarding specific cognitive functions exist in the normal population, we hypothesize that the application of gendercorrected Z scores may change this profile, indicating that interpretations derived from raw-score analysis have to be questioned with regard to disease specificity.

\section{Method}

\section{LANDSCAPE database}

The LANDSCAPE study is a multicentre, prospective, observational cohort study of PD patients that focuses on the natural progression of cognitive impairment in $\mathrm{PD}$ and on the identification of factors that contribute to the evolution and/or progression of cognitive impairment. Patients were recruited in eight specialized movement disorder centres across Germany (Aachen, Bonn, Dresden, Frankfurt/Main, Kassel, Kiel, Marburg, Tübingen) and assessed with a comprehensive clinical and neuropsychological test battery, as well as blood tests and neuroimaging procedures for a subset of patients. More detailed information can be found in Balzer-Geldsetzer et al. (2011).

\section{Participants}

To be eligible for enrolment in the LANDSCAPE study, participants had to be aged between 45 and 80 years and meet the criteria for the diagnosis of idiopathic PD according to the UK Parkinson's Disease Society Brain Bank clinical diagnostic criteria (Hughes et al. 1992). With regard to cognitive impairment, diagnosis of PD-MCI was defined according to the criteria proposed by Petersen (2004), and PD-D was diagnosed according to the consensus guidelines by Emre et al. (2007), operationalized by Dubois et al. (2007).

\section{Cognitive assessment and operationalization of PD, PD-MCI and PD-D}

Neuropsychological assessment was carried out by trained neuropsychologists. The neuropsychological examination was conducted in the patients' on-phase after medication. Global cognitive functions were assessed with the MMSE (Folstein et al. 1975), the Parkinson Neuropsychometric Assessment (PANDA; Kalbe et al. 2007, 2008), and the CERAD total score (based on Chandler et al. 2005). Specific cognitive functions were assessed using the CERAD-Plus test (Aebi, 2002). In this battery, verbal memory is tested with the subtests word-list learning, delayed recall and recognition of the word list, while figural memory is assessed with the delayed recall of copied figures (nonverbal memory). Executive functions are tested with the phonemic (letter S) and semantic (animals) verbal fluency subtests and the Trail-Making Test (TMT) $\mathrm{B} / \mathrm{A}$ index. Visuospatial abilities are tested using the constructional praxis subtest in which figures have to be copied. Finally, language is assessed with the Boston Naming Test (BNT). Next to the CERAD-Plus, five additional tests were used in the neuropsychological test battery of the LANDSCAPE project: the Modified Card Sorting Test (executive functions), the Stroop interference test (Bäumler, 1985), the Brief Test of Attention (BTA; Schretlen, 1997; both attention), and the subtests Mental Rotation and Spatial Imagination from the German test battery 'Leistungsprüfsystem 50+' (Sturm et al. 1993; visuospatial functions). Cognitive dysfunction was operationalized by scores of $\leqslant-1.5$ standard deviations (S.D.) below the mean in at least one neuropsychological test score. Patients without cognitive dysfunction were classified as PD patients without cognitive impairment (PD-N). PD-MCI criteria according to Petersen (2004) were operationalized as follows: (1) a diagnosis of PD according to Queen Square Brain Bank criteria; (2) a subjective complaint of cognitive decline by the patient, preferably 
corroborated by a reliable source, in medical history; (3) no or minimal impact of the decline on acitivities of daily living according to medical history, and the absence of dementia; and (4) objective evidence of cognitive abnormalities in neuropsychological tests. PD-D criteria according to Emre et al. (2007) and operationalized by Dubois et al. (2007) were: (1) a diagnosis of PD according to Queen Square Brain Bank criteria; (2) insidious onset and slow progression of cognitive deficits; (3) deficits that are severe enough to impair daily life independent of the impairment ascribable to motor symptoms; (4) objective impairment in at least two cognitive domains as demonstrated by a deficit in at least one test per domain; and (5) cognitive impairment represents a decline from the premorbid level.

\section{CERAD-Plus test battery}

As indicated above, the analysis of gender differences in cognitive functions was based on the results of the CERAD-Plus test battery, as it provides raw scores as well as age, education, and - most important for our study - gender-corrected normative scores ( $Z$ scores) for all subtests, derived from a large database of healthy control subjects (Aebi, 2002). The normative sample included 690 men and 410 women. Men were on average aged 69.9 (S.D.=7.5) years and had 13.2 (S.D. $=3.0)$ years of formal education. Women had a mean age of 67.1 (S.D. $=8.1$ ) years and had 11.3 (S.D. = 2.5) years of education. Raw scores are transformed into $Z$ scores based on three age groups, two education groups and gender.

\section{Clinical assessment}

Duration of symptoms, the date of initial diagnosis and medication were recorded. To define motor impairment, the Unified Parkinson's disease Rating Scale (part III; Fahn, 1987), and the Hoehn \& Yahr (1967) scale were used. The short form of the geriatric depression scale (GDS-15; Burke et al. 1991), a 15-item selfevaluation questionnaire, was used to assess depressive symptoms. Total dopaminergic treatment was calculated as the L-dopa equivalent daily dose (LEDD) according to the formula proposed by Tomlinson et al. (2010).

\section{Ethical approval}

The study was conducted in compliance with the World Medical Association Declaration of Helsinki (1997). The study protocol was approved by the Ethics Committee of Philipps University Marburg (approval no. 178/07) in March 2009 and subsequently by the local ethics committees of the participating centres in Germany.

\section{Statistical analyses}

Differences in demographic and clinical characteristics between men and women with PD, as well as gender differences in global cognition, were tested using Student's $t$ test and, if necessary, the non-parametric Wilcoxon signed-rank test.

All analyses were performed for the whole group of PD patients and for each diagnostic group separately (PD-N, PD-MCI, PD-D). Levene's test was used to verify homogeneity of variances. The analysis was carried out in two steps: (1) the association between gender and raw values on the individual neuropsychological tests was evaluated with analysis of covariance (ANCOVA). The following covariates were controlled for: age, disease duration, UPDRS III, GDS-15 score, and LEDD. (2) Gender comparisons of the corrected $Z$ scores for the individual neuropsychological tests were performed using ANCOVA. In this analysis, again disease duration, UPDRS III, GDS-15 score, and LEDD were controlled for. Age was not used here, since $Z$ scores were already age-corrected. Even though ANCOVA is known to be robust against a disturbance of the assumption, we verified the results by the non-parametric rank ANCOVA from Quade (1967). The alpha level was set to 0.05 for all tests. Statistical data analysis was carried out by study-independent statisticians using SAS v. 9.4 (SAS Institute Inc., USA).

\section{Results}

\section{Demographic and clinical characteristics, global cognitive functions}

As indicated in Table 1, male and female PD patients had comparable age, disease duration, age at symptom onset and depression scores (GDS-15), but men had significantly more motor impairment than women (UPDRS III; $p=0.006$ ) and more years of education ( $p$ $<0.0001)$. Importantly, these differences are not relevant for our analysis as the variables were used as covariates. For global cognitive functions, male and female PD patients had comparable overall cognitive states both indicated by the MMSE and the PANDA, but women had slightly higher CERAD total scores $(p=$ 0.02).

Comparison of the diagnostic groups showed that men had significantly more education in all three groups (PD-N: $p<0.0001$; PD-MCI: $p<0.0001$; PD-D: $p=0.002$ ). Women in the PD-MCI group had a significantly longer disease duration $(p=0.01)$ and men in the PD-N group had a higher UPDRS III score $(p=0.005)$. Women in the PD-D group took a lower dose of 
Table 1. Comparisons of clinical and demographic variables between male and female PD patients, whole sample and per diagnostic group

\begin{tabular}{|c|c|c|c|c|c|c|c|c|c|c|c|c|}
\hline & \multicolumn{3}{|c|}{ All patients $(n=656)$} & \multicolumn{3}{|c|}{ PD-N $(n=267)$} & \multicolumn{3}{|c|}{ PD-MCI $(n=292)$} & \multicolumn{3}{|c|}{ PD-D $(n=97)$} \\
\hline & M & $\mathrm{F}$ & $p$ & $M(n=177)$ & $F(n=90)$ & $p$ & $M(n=201)$ & $F(n=91)$ & $p$ & $M(n=67)$ & $F(n=30)$ & $P$ \\
\hline Age (years) & $67.9(7.8)$ & $67.2(7.8)$ & 0.13 & $65.6(8.7)$ & $65.4(7.8)$ & 0.48 & $68.3(7.1)$ & $67.6(7.7)$ & 0.38 & $72.4(4.9)$ & $71.6(6.0)$ & 0.42 \\
\hline Education (years) & $10.6(1.7)$ & $10.1(1.7)$ & $<0.0001$ & $10.8(1.6)$ & $10.5(1.7)$ & $<0.0001$ & $10.5(1.69)$ & $9.7(1.4)$ & $<0.0001$ & $13.0(2.0)$ & $11.0(1.8)$ & 0.002 \\
\hline Disease duration (years) & $6.9(5.5)$ & $6.8(5.2)$ & 0.96 & $5.9(4.6)$ & $5.1(4.6)$ & 0.12 & $6.7(5.5)$ & $8.2(5.3)$ & 0.01 & $9.9(6.8)$ & $7.5(5.6)$ & 0.09 \\
\hline Age at onset (years) & $59.5(8.9)$ & $58.9(9.0)$ & 0.26 & $58.4(9.2)$ & $58.6(8.8)$ & 0.86 & $59.9(8.9)$ & $58.0(9.3)$ & 0.09 & $61.4(7.8)$ & $62.9(8.1)$ & 0.42 \\
\hline Hoehn \& Yahr stage & $2.3(0.8)$ & $2.3(0.9)$ & 0.92 & $2.1(0.7)$ & $2.0(0.6)$ & 0.22 & $2.3(0.9)$ & $2.4(0.9)$ & 0.43 & $2.8(0.9)$ & $3.0(0.8)$ & 0.43 \\
\hline UPDRS III & $24.4(12.6)$ & $21.4(11.1)$ & 0.006 & $21.6(11.0)$ & $17.7(9.1)$ & 0.005 & $24.2(12.6)$ & $22.7(10.0)$ & 0.54 & $32.5(13.3)$ & $29.0(15.1)$ & 0.08 \\
\hline GDS-15 score & $3.4(3.1)$ & $3.5(2.9)$ & 0.38 & $2.8(2.8)$ & $2.6(2.4)$ & 0.63 & $3.0(2.6)$ & $3.6(2.7)$ & 0.05 & $6.4(3.6)$ & $6.0(3.5)$ & 0.68 \\
\hline LEDD (mg/day) & $800.5(557.5)$ & $709.1(463.4)$ & 0.11 & $733.5(539.8)$ & $504.0(25.4)$ & 0.36 & $816.9(572.5)$ & $794.2(438.3)$ & 0.50 & $930.4(539.8)$ & $669.7(376.2)$ & 0.04 \\
\hline MMSE & $27.8(2.3)$ & $28.1(2.2)$ & 0.07 & $28.8(1.2)$ & $28.9(1.5)$ & 0.09 & $28.0(1.7)$ & $28.1(1.8)$ & 0.72 & $24.5(2.9)$ & $25.5(3.0)$ & 0.02 \\
\hline PANDA & $21.2(6.2)$ & $22.2(5.7)$ & 0.14 & $24.5(4.3)$ & $25.4(3.8)$ & 0.13 & $21.1(5.1)$ & $21.3(5.1)$ & 0.69 & $13.0(5.8)$ & $15.0(4.7)$ & 0.10 \\
\hline CERAD total score & $75.6(13.0)$ & $77.6(13.7)$ & 0.02 & $84.0(7.7)$ & $86.2(7.0)$ & 0.05 & $74.1(9.9)$ & $76.3(10.3)$ & 0.10 & $56.7(11.8)$ & $55.8(12.6)$ & 0.73 \\
\hline
\end{tabular}

PD-N, PD patients with no cognitive impairment; PD-MCI, PD patients with mild cognitive impairment; PD-D, PD patients with Parkinson's disease dementia; M, male; F, female; UPDRS III, Unified Parkinson Disease Rating Scale III; GDS-15, Geriatric Depression Scale (short version); LEDD, L-dopa equivalent daily dose; MMSE, Mini Mental State Examination; PANDA, Parkinson Neuropsychometric Assessment; CERAD, Consortium to establish a diagnosis of Alzheimer's disease.

Data are given as mean \pm standard deviation. 
Verbal learning

(a)

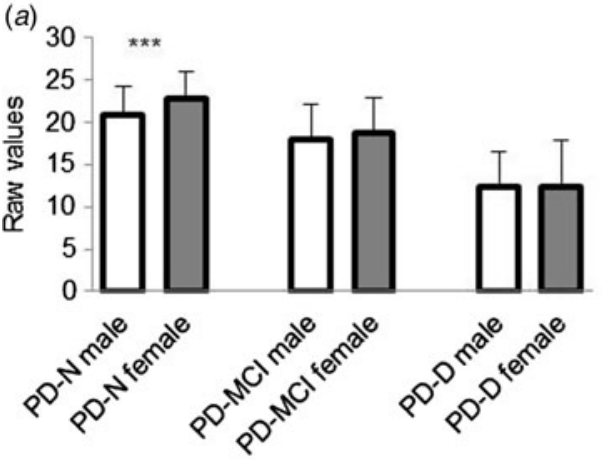

Verbal recall

(b)

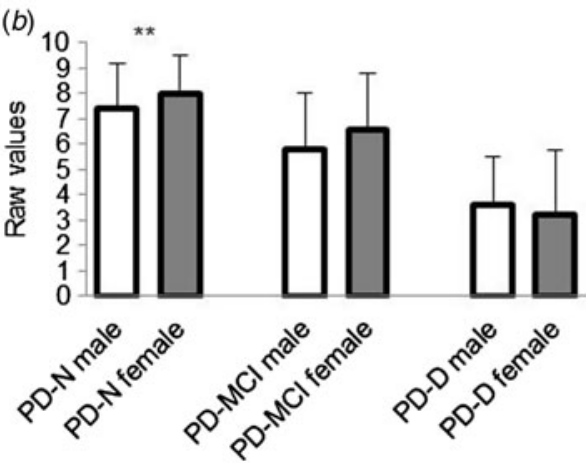

(c)
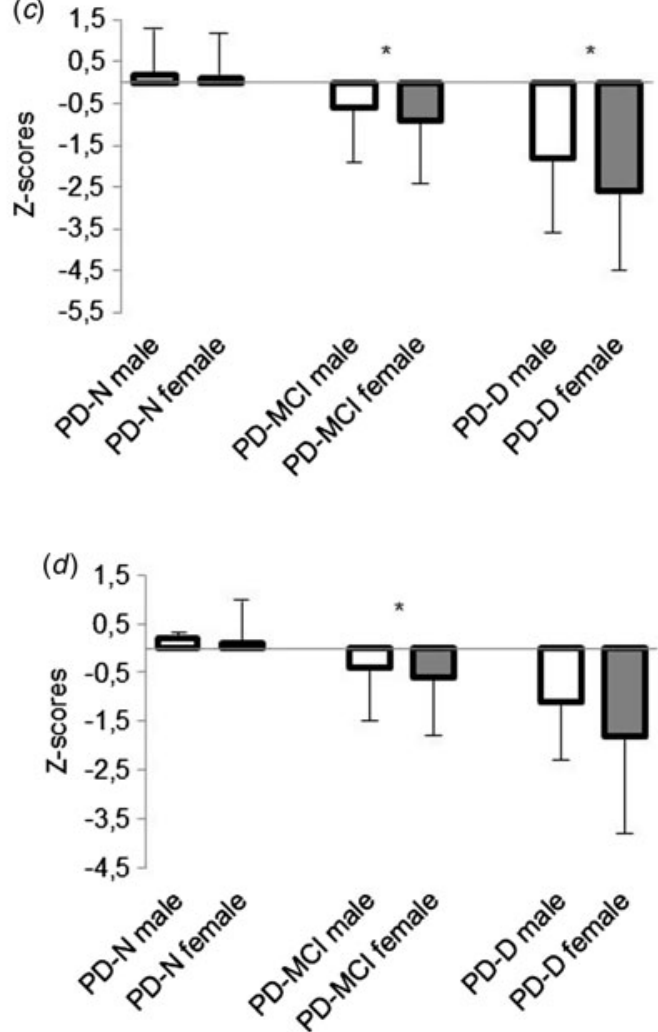

Fig. 1. Gender comparison of verbal learning and verbal recall for PD patients per cognitive group. Means and standard deviations are shown. (a) Raw values on verbal learning; (b) raw values on verbal recall; $(c) Z$ scores on verbal learning; (d) $\mathrm{Z}$ scores on verbal recall.

LEDD ( $p=0.04)$ and had lower MMSE scores $(p=0.02)$. Again, these variables were used as covariates in the analyses so that gender differences did not hamper our main analysis of cognitive functions. Finally, men in the PD-N group had lower CERAD total scores $(p$ $=0.05$ ). All other variables were comparable between genders within cognitive groups.

\section{Neuropsychological tests: raw-score analysis}

Overall group raw-score analysis (Supplementary Table S1) showed that women performed better on the verbal learning $(p=0.01)$ and verbal recall $(p=$ 0.02) tasks, whereas men outperformed women on the visuoconstructive test (constructional praxis, $p=$ 0.002 ) and figural memory (recall of figures, $p=0.006$ ).

The differentiated group analysis demonstrated that women's superiority in verbal learning and verbal recall was only significant in the PD-N group ( $p=$ 0.0005 and $p=0.008$, respectively), while there were no differences in the two groups with cognitive impairment (PD-MCI, PD-D), indicating that gender-related differences in raw scores of verbal memory tests are most evident in higher levels of cognitive functions and decrease with increasing cognitive deterioration
(Fig. 1a,b). In the visuospatial domain (constructional praxis and figural memory), men significantly outperformed women only in the PD-MCI group $(p=0.002$ and $p=0.01$, respectively), while no significant differences were found in the other groups (Supplementary Table S2). There was a trend towards statistical significance in the phonemic verbal fluency test in which women scored higher. This trend was found in the overall group analysis $(p=0.06)$ and the PD-MCI group $(p=0.08)$. No other differences between men and women in raw scores of the other memory, executive, or language tests were found.

\section{Neuropsychological tests: Z-score analysis}

The pattern that emerged in Z-score analyses was substantially different from that in the raw-score analysis. In the overall patient group analysis, men had significantly higher $Z$ scores on all three verbal memory tests, i.e. verbal learning $(p=0.04)$, verbal recall $(p=0.02)$ and verbal recognition ( $p=0.05$, Supplementary Table S1). In contrast, there were no significant differences between men and women for the visuospatial tasks.

The differentiated group analysis showed a similar picture: men were significantly superior to women in 
verbal learning and verbal recall in the PD-MCI group ( $p=0.02$ and $p=0.04$, respectively) and for verbal learning also in the PD-D group $(p=0.04$, Fig. $1 c, d)$, indicating that, in contrast to the pattern from raw scores, differences in the performance of men and women were more distinct in patients with cognitive impairment. As a further result, women in the PD-N group were significantly better in the BNT $(p=0.01$, Supplementary Table S2).

No other differences in $Z$ scores between men and women in any other executive or visuospatial test were found.

\section{Discussion}

One main finding of this analysis of a large cohort of 656 patients with PD-N, PD-MCI or PD-D including 445 male and 211 female individuals is that the genderspecific cognitive pattern described in other studies could be replicated based on a raw-score analysis. This means women perform better in verbal memory while men outperform women in visuospatial abilities. This could be demonstrated both in the analysis of the overall group as well as for the differentiated group analysis (for the PD-N group for verbal learning and verbal recall and for the PD-MCI group for visuospatial skills). The second main finding of our study is that gender-corrected Z-score analysis showed a markedly different pattern. More specifically, women were more affected in verbal memory while the difference between genders in visuospatial skills disappeared. This was demonstrated in the overall analysis and the differentiated analysis - for verbal learning in both impaired groups (PD-MCI and PD-D), for verbal recall only in PD-MCI and for visuospatial skills in all three groups. These findings give rise to two substantial points for discussion: the first is the phenomenon of the pattern of cognitive gender differences obtained by raw-score and Z-score analyses that changes and even swaps. The second is the question of why verbal memory declines more in women with PD.

The fact that using gender-corrected normative data changes the picture of gender-specific cognitive profiles in such a substantial way is striking. It is important to note that our raw-score analysis is in line with previous studies showing that women with PD outperform men with PD in the verbal memory domain, while male patients are superior in visuospatial tasks (Carey et al. 2002; Locascio et al. 2003; Pasotti et al. 2012; Szewczyk-Krolikowski et al. 2014). None of these studies corrected the data for gender. For example, in the largest study so far in the field with a sample of 306 PD patients, Pasotti et al. (2012) used age- and education- but not gender-corrected scores and reported that women had higher verbal learning scores and men were superior in the visuospatial domain. Importantly, although these gender-specific cognitive profiles in PD patients based on raw-score analyses are consistent with typical gender-specific cognitive profiles in healthy subjects (Munro et al. 2012) and could thus simply represent a drop of 'normal' performance, they have been interpreted as PD related. However, our gender-corrected Z-score analysis clearly demonstrates that raw-score analyses are misleading and that interpretation of these profiles should be made with caution. We conclude that the profile described so far may have to be revised. Interestingly, in a comment on the above-mentioned study by Szewczyk-Krolikowski et al. (2014), Picillo et al. (2014) have already criticized the lack of a direct comparison of non-motor symptoms between healthy men and male PD patients and between healthy women and female PD patients and stated that the comparison of patient data to an appropriate reference group (as is available via $Z$ scores) would be 'the benchmark in revealing the effect of gender on nonmotor symptoms in PD'. However, although the addressed working group performed an additional analysis of their data in response to this comment (Ben-Shlomo et al. 2014), both analyses yielded comparable results, i.e. men with PD were more affected in global cognition, assessed with the MoCA, and in verbal fluency. Unfortunately, no data of verbal memory and visuospatial processing were included, so their data cannot be compared to the main results of the present study.

Although not included in our hypotheses, in an exploratory way we tested for differences in all cognitive domains assessed with the CERAD beyond verbal memory and visuospatial functions and found a significant difference between men and women in the $Z$ scores of the BNT in one of the subgroups (PD-N), but not in the overall group comparison or the rawscore analysis: women in the PD-N group had significantly higher $Z$ scores in the BNT. Remarkably, in the PD-N group, the corresponding raw values of women and men were exactly the same. Thus it can be assumed that in the healthy population, and accordingly also in the normative data of the CERAD (Aebi, 2002), men have slightly higher scores in the BNT - a result that has also been found in other studies (Welch et al. 1996; Zec et al. 2007). Thus, our data indicate that women with PD-N performed slightly better than expected. However, it should be noted that the difference between men and women is not clinically relevant, as $Z$ scores were higher than 0 . Nevertheless, this aspect is worth pursuing in future studies.

Our findings demonstrate that the use of tests with gender- but also age- and education-corrected norms 
may enhance diagnostic accuracy in PD patients. Markedly, out of all neuropsychological tests that were recommended for the diagnostic procedure of PD-MCI (Litvan et al. 2011) and PD-D (Dubois et al. 2007) from the Movement Disorder Society Task force, only one test, the TMT to assess (motor dependent) cognitive speed and set-shifting as an important executive function, provides gender-corrected normative data published by Tombaugh (2004). Thus, particular awareness of this issue would be valuable when selecting test instruments for clinical and research purposes - not just concerning age and education, but also gender.

Our result, based on $Z$ scores, that verbal memory declines more in women is intriguing. Markedly, although longitudinal data are not yet available from our patients, the cross-sectional data provide preliminary evidence that this decline may accelerate from the stage of PD-MCI to that of PD-D, as the discrepancy between men and women increases. In other words, the strength in verbal memory that healthy women and female PD patients without cognitive impairment typically show first disappears, and in later stages this domain even becomes the most vulnerable.

One possible explanation for this finding is that the so-called cognitive reserve, i.e. the resistance against brain pathology, differs in men and women. As cognitive reserve is closely related to education (Stern, 2009), which is usually lower in women and has also been related to cognitive functions in PD patients (Hindle et al. 2014), it can be hypothesized that this accounts for the cognitive disadvantage in women with increasing pathology. In fact, education is significantly lower in our female compared to male patients. One could argue that this explanation should be ruled out, as the $Z$ scores used in our analysis were corrected for education. However, education does not fully capture the concept of cognitive reserve; rather, beyond formal education it strongly relies on cognitive engagement over the lifespan (Valenzuela et al. 2008; Stern, 2009). Thus, as we have no relevant information beyond education, further research taking into account additional aspects of cognitive reserve is needed to clarify this issue. If cognitive reserve turns out to be critical, it also has to be examined why specifically verbal memory is affected more in women while other cognitive domains are affected equally in both genders.

Another possible explanation for the results pertains to the effects of endogenous sex hormones. A specific role of oestrogen seems reasonable given the body of evidence showing that the oestrogen level is related to verbal memory performance (Boss et al. 2014), that verbal memory typically declines in older women when oestrogen levels decrease and that oestrogen replacement therapy prevents this decline (Sherwin, 2012). However, this development presumably also applies to healthy women, so it can be expected that the age-corrected $Z$ scores used in our study correct for this phenomenon. However, as we have no information on oestrogen levels or oestrogen replacement therapy in our patient sample and as this aspect is also not considered in the description of the sample examined as the reference group, no clear conclusions can be drawn.

An additional hypothesis that has been proposed to explain gender-specific cognitive dysfunction in PD is that there are differential effects of levodopa treatment on men and women, which has for example been discussed for visuospatial processing (Lyons et al. 1998; Carey et al. 2002). Furthermore, Carey et al. (2002) argued that if men are endowed with more visuospatial processing resources compared to women (Weiss et al. 2003; de Frias et al. 2006) and if PD does have a specific deleterious effect on visuospatial function (Bradley et al. 1989), it is only logical that men tend to suffer a greater loss in this domain.

Interestingly, greater decline in verbal memory in female patients has also been described in other neurodegenerative disorders including Alzheimer's disease (AD; Chapman et al. 2011; Pusswald et al. 2015). Different hypotheses for this finding have been postulated, including the post-menopausal decrease in oestrogen levels (Henderson et al. 1996), as well as less cognitive reserve in females (Chapman et al. 2011), but also other explanations such as a more frontal metabolic impairment in women with AD (Herholz et al. 2002), differences regarding topography and severity or cerebral perfusion, smaller volumes of the hippocampus and other structures in women with AD (Kidron et al. 1997; Callen et al. 2001, 2004; Ballmaier et al. 2004) and differential effects of the apolipoprotein E (APOE)4 allele (Fleisher et al. 2005). However, none of these hypotheses have been examined for gender-specific cognitive symptoms in PD patients yet. In summary, although several potential reasons for PD-related gender differences in cognition in general and specifically verbal memory can be considered, the current state of research is rudimentary and further comprehensive studies are necessary. This also seems important from another perspective: it is not executive dysfunction which is the most frequent symptom in PD in most (but not all) studies and is ascribed to dopaminergic dysfunction in the 'cognitive' frontostriatal circuit (Moustafa \& Poletti, 2013), but 'non-dopaminergic' memory impairment that is regarded as a predictor of PD-D (Kehagia et al. 2013). Thus, the gender-specific decline in memory should be taken into account in studies examining the progression from PD-MCI to PD-D. 
Despite a very careful study design, the present study may have several limitations. First, our neuropsychological test battery was limited, as both visuoconstruction and figural memory were tested with only one test each. Furthermore, the domain of attention was not sufficiently covered. Thus, future studies using a more elaborate test battery assessing more subfunctions of relevant domains may have even higher sensitivity to detect gender-specific cognitive differences. Second, with regard to the development of affected domains, it should be noted that longitudinal data from our patients were not available, so genderspecific progression of cognitive decline was derived by comparing independent samples of patients with different cognitive stages, i.e. a cross-sectional design was used. Future studies should include follow-up data because only longitudinal data allow interpretation of intra-individual changes of cognitive functions that can then be compared between genders. Third, severely demented PD patients were not included, limiting conclusions to only mild stages of PD-D. Finally, the recently established PD-MCI criteria according to Litvan et al. (2012) were not used, as these criteria were published after onset of the LANDSCAPE study. Using these PD-specific criteria in further research may affect findings on gender-specific cognitive profiles.

The strengths of this study are the large database of prospectively included PD patients, assessed with a homogeneous study protocol, the differentiation of various cognitive stages of PD patients, the use of an established cognitive test battery, which provides gender- (and also age- and education-) corrected normative data based on a large reference cohort of healthy controls, and the fact that potential confounding factors including sociodemographic and clinical/ motor data are controlled for in our analysis. Most importantly, to our knowledge, this is the first study comparing raw scores and $Z$ scores of cognitive measures in a PD population.

In conclusion, the results of our study disclose that in contrast to the findings of previous studies, women may be more detrimentally affected by PD in verbal memory, and this effect may increase with the progression of cognitive dysfunction. Furthermore, also in contrast to previous results, men and women with PD seem not to be differentially affected in the visuospatial domain. Finally, the fact that our Z-score analysis showed markedly different results compared to the raw-score analysis used so far suggests that the use of gender-corrected and, of course, also ageand education-corrected norms in neuropsychological testing is important both in scientific studies as well as in clinical settings in order to enhance the diagnostic accuracy.

\section{Supplementary material}

The supplementary material for this article can be found at http://dx.doi.org/10.1017/S0033291716000908.

\section{Acknowledgements}

The authors thank all patients participating in the study and all staff members in the recruiting centres who contributed to the study. We especially thank the study nurses Helga Peter, Ute Rockel, Birte Hackelberg, Dorothea Hueske, and Regina Jordan. The DEMPARK study is funded by an unrestricted grant from Novartis and a grant from the International Parkinson Fonds (Deutschland) GmbH (IPD). The continuation of the study (LANDSCAPE) is part of the Competence Network Degenerative Dementias and is funded by the German Ministry for Education and Research (BMBF; project no. 01GI1008C).

\section{Declaration of Interest}

None.

\section{References}

Aarsland D, Bronnick K, Williams-Gray C, Weintraub D, Marder K, Kulisevsky J, Burn D, Barone P, Pagonabarraga J, Allcock L, Santangelo G, Foltynie T, Janvin C, Larsen JP, Barker RA, Emre M (2010). Mild cognitive impairment in Parkinson disease: a multicenter pooled analysis. Neurology 75, 1062-1069.

Abate KH (2013). Gender disparity in prevalence of depression among patient population: a systematic review. Ethiopian Journal of Health Sciences 23, 283-288.

Aebi C (2002). Validierung der neuropsychologischen Testbatterie CERAD-NP: eine Multi-Center Studie. Basel: Ph.D. thesis, University of Basel.

Amick MM, Schendan HE, Ganis G, Cronin-Golomb A (2006). Frontostriatal circuits are necessary for visuomotor transformation: mental rotation in Parkinson's disease. Neuropsychologia 44, 339-349.

Ballmaier M, O'Brien JT, Burton EJ, Thompson PM, Rex DE, Narr KL, McKeith IG, DeLuca H, Toga AW (2004). Comparing gray matter loss profiles between dementia with Lewy bodies and Alzheimer's disease using cortical pattern matching: diagnosis and gender effects. Neuroimage 23, 325-335.

Balzer-Geldsetzer M, Costa AS, Kronenburger M, Schulz JB, Roske S, Spottke A, Wullner U, Klockgether T, Storch A, Schneider C, Riedel O, Wittchen HU, Seifried C, Hilker R, Schmidt N, Witt K, Deuschl G, Mollenhauer B, Trenkwalder C, Liepelt-Scarfone I, Graber-Sultan S, Berg D, Gasser T, Kalbe E, Bodden M, Oertel WH, Dodel R (2011). Parkinson's disease and dementia: a longitudinal study (DEMPARK). Neuroepidemiology 37, 168-176.

Bäumler G (1985). Farb-Wort-Interferenztest (FWIT) after J. R. Stroop. Hogrefe: Göttingen. 
Ben-Shlomo Y, Lawton M, Szewczyk-Krolikowski K, Hu MT (2014). Letter in response to Picillo et al. in relation to Szewczyk-Krolikowski et al.: the influence of age and gender on motor and non-motor features of early Parkinson's disease: initial findings from the Oxford Parkinson disease Center (OPDC) discovery cohort. Parkinsonism and Related Disorders 20, 1321-1322.

Boss L, Kang DH, Marcus M, Bergstrom N (2014). Endogenous sex hormones and cognitive function in older adults: a systematic review. Western Journal of Nursing Research 36, 388-426.

Bradley VA, Welch JL, Dick DJ (1989). Visuospatial working memory in Parkinson's disease. Journal of Neurology, Neurosurgery and Psychiatry 52, 1228-1235.

Burke WJ, Roccaforte WH, Wengel SP (1991). The short form of the Geriatric Depression Scale: a comparison with the 30-item form. Journal of Geriatric Psychiatry and Neurology 4, 173-178.

Callen DJ, Black SE, Caldwell CB, Grady CL (2004). The influence of sex on limbic volume and perfusion in AD. Neurobiology of Aging 25, 761-770.

Callen DJ, Black SE, Gao F, Caldwell CB, Szalai JP (2001). Beyond the hippocampus: MRI volumetry confirms widespread limbic atrophy in AD. Neurology 57, 1669-1674.

Carey JR, Deskin KA, Josephson KT, Wichmann RL (2002). Sex differences in tracking performance in patients with Parkinson's disease. Archives of Physical Medicine and Rehabilitation 83, 972-977.

Chandler MJ, Lacritz LH, Hynan LS, Barnard HD, Allan G, Deschner M, Weiner MF, Cullum CM (2005). A total score for the CERAD neuropsychological battery. Neurology 65, 102-106.

Chapman RM, Mapstone M, Gardner MN, Sandoval TC, McCrary JW, Guillily MD, Reilly LA, DeGrush E (2011). Women have farther to fall: gender differences between normal elderly and Alzheimer's disease in verbal memory engender better detection of Alzheimer's disease in women. Journal of the International Neuropsychological Society 17, 654-662.

Crizzle AM, Classen S, Uc EY (2012). Parkinson disease and driving: an evidence-based review. Neurology 79, 20672074.

de Frias CM, Nilsson LG, Herlitz A (2006). Sex differences in cognition are stable over a 10-year period in adulthood and old age. Neuropsychology, Development, and Cognition. Section B, Aging, Neuropsychology and Cognition 13, 574-587.

de Lau LM, Giesbergen PC, de Rijk MC, Hofman A, Koudstaal PJ, Breteler MM (2004). Incidence of parkinsonism and Parkinson disease in a general population: the Rotterdam Study. Neurology 63, 1240-1244.

Dubois B, Burn D, Goetz C, Aarsland D, Brown RG, Broe GA, Dickson D, Duyckaerts C, Cummings J, Gauthier S, Korczyn A, Lees A, Levy R, Litvan I, Mizuno Y, McKeith IG, Olanow CW, Poewe W, Sampaio C, Tolosa E, Emre M (2007). Diagnostic procedures for Parkinson's disease dementia: recommendations from the movement disorder society task force. Movement Disorders 22, 2314-2324.

Emre M, Aarsland D, Brown R, Burn DJ, Duyckaerts C, Mizuno Y, Broe GA, Cummings J, Dickson DW, Gauthier S,
Goldman J, Goetz C, Korczyn A, Lees A, Levy R, Litvan I, McKeith I, Olanow W, Poewe W, Quinn N, Sampaio C, Tolosa E, Dubois B (2007). Clinical diagnostic criteria for dementia associated with Parkinson's disease. Movement Disorders 22, 1689-1707; quiz 1837.

Fahn S (1987). Unified Parkinson's disease rating scale. In Recent Developments in Parkinson's Disease (ed. S. Fahn, C. D. Marsden, M. Goldstein and D. B. Calne), pp. 153-163. Macmillian Healthcare Information: Florham Park.

Fleisher A, Grundman M, Jack Jr. CR, Petersen RC, Taylor C, Kim HT, Schiller DH, Bagwell V, Sencakova D, Weiner MF, DeCarli C, DeKosky ST, van Dyck CH, Thal LJ (2005) Sex, apolipoprotein E epsilon 4 status, and hippocampal volume in mild cognitive impairment. Archives of Neurology 62, 953-957.

Folstein MF, Folstein SE, McHugh PR (1975). “Mini-mental state". A practical method for grading the cognitive state of patients for the clinician. Journal of Psychiatric Research 12, 189-198.

Haaxma CA, Bloem BR, Borm GF, Oyen WJ, Leenders KL, Eshuis S, Booij J, Dluzen DE, Horstink MW (2007). Gender differences in Parkinson's disease. Journal of Neurology, Neurosurgery and Psychiatry 78, 819-824.

Hariz GM, Lindberg M, Hariz MI, Bergenheim AT (2003). Gender differences in disability and health-related quality of life in patients with Parkinson's disease treated with stereotactic surgery. Acta Neurologica Scandinavica 108, 28-37.

Heller J, Dogan I, Schulz JB, Reetz K (2013). Evidence for gender differences in cognition, emotion and quality of life in Parkinson's disease? Aging and Disease 22, 63-75.

Henderson VW, Watt L, Buckwalter JG (1996). Cognitive skills associated with estrogen replacement in women with Alzheimer's disease. Psychoneuroendocrinology 21, 421-430.

Herholz K, Schopphoff H, Schmidt M, Mielke R, Eschner W, Scheidhauer K, Schicha H, Heiss WD, Ebmeier K (2002). Direct comparison of spatially normalized PET and SPECT scans in Alzheimer's disease. Journal of Nuclear Medicine 43, 21-26.

Hindle JV, Martyr A, Clare L (2014). Cognitive reserve in Parkinson's disease: a systematic review and meta-analysis. Parkinsonism and Related Disorders 20, 1-7.

Hoehn MM, Yahr MD (1967). Parkinsonism: onset, progression and mortality. Neurology 17, 427-442.

Hu MT, Szewczyk-Krolikowski K, Tomlinson P, Nithi K, Rolinski M, Murray C, Talbot K, Ebmeier KP, Mackay CE, Ben-Shlomo Y (2014). Predictors of cognitive impairment in an early stage Parkinson's disease cohort. Movement Disorders 29, 351-359.

Hughes AJ, Daniel SE, Kilford L, Lees AJ (1992). Accuracy of clinical diagnosis of idiopathic Parkinson's disease: a clinico-pathological study of 100 cases. Journal of Neurology, Neurosurgery and Psychiatry 55, 181-184.

Kalbe E, Calabrese P, Kohn N, Hilker R, Riedel O, Wittchen HU, Dodel R, Otto J, Ebersbach G, Kessler J (2008). Screening for cognitive deficits in Parkinson's disease with the Parkinson neuropsychometric dementia assessment (PANDA) instrument. Parkinsonism and Related Disorders 14, 93-101. 
Kalbe E, Riedel O, Kohn N, Dodel R, Calabrese P, Kessler J (2007). Sensitivity and Specificity of the "Parkinson Neuropsychometric Dementia Assessment" (PANDA): Results of the GEPAD Study [German]. Aktuelle Neurologie 34, 140-146.

Kehagia AA, Barker RA, Robbins TW (2013). Cognitive impairment in Parkinson's Disease: the dual syndrome hypothesis. Neurodegenerative Diseases 11, 79-92.

Kidron D, Black SE, Stanchev P, Buck B, Szalai JP, Parker J, Szekely C, Bronskill MJ (1997). Quantitative MR volumetry in Alzheimer's disease. Topographic markers and the effects of sex and education. Neurology 49, 15041512.

Leentjens AF, Moonen AJ, Dujardin K, Marsh L, Martinez-Martin P, Richard IH, Starkstein SE, Kohler S (2013). Modeling depression in Parkinson disease: disease-specific and nonspecific risk factors. Neurology $\mathbf{8 1}$, 1036-1043.

Litvan I, Aarsland D, Adler CH, Goldman JG, Kulisevsky J, Mollenhauer B, Rodriguez-Oroz MC, Troster AI, Weintraub D (2011). MDS Task Force on mild cognitive impairment in Parkinson's disease: critical review of PD-MCI. Movement Disorders 26, 1814-1824.

Litvan I, Goldman JG, Troster AI, Schmand BA, Weintraub D, Petersen RC, Mollenhauer B, Adler CH, Marder K, Williams-Gray CH, Aarsland D, Kulisevsky J, Rodriguez-Oroz MC, Burn DJ, Barker RA, Emre M (2012). Diagnostic criteria for mild cognitive impairment in Parkinson's disease: Movement Disorder Society Task Force guidelines. Movement Disorders 27, 349-356.

Locascio JJ, Corkin S, Growdon JH (2003). Relation between clinical characteristics of Parkinson's disease and cognitive decline. Journal of Clinical and Experimental Neuropsychology 25, 94-109.

Lyons KE, Hubble JP, Troster AI, Pahwa R, Koller WC (1998). Gender differences in Parkinson's disease. Clinical Neuropharmacology 21, 118-121.

Miller IN, Cronin-Golomb A (2010). Gender differences in Parkinson's disease: clinical characteristics and cognition. Movement Disorders 25, 2695-2703.

Moustafa AA, Poletti M (2013). Neural and behavioral substrates of subtypes of Parkinson's disease. Frontiers in Systems Neuroscience 7, 117.

Munro CA, Winicki JM, Schretlen DJ, Gower EW, Turano KA, Munoz B, Keay L, Bandeen-Roche K, West SK (2012). Sex differences in cognition in healthy elderly individuals. Neuropsychology, Development, and Cognition. Section B, Aging, Neuropsychology and Cognition 19, 759-768.

Nazem S, Siderowf AD, Duda JE, Have TT, Colcher A, Horn SS, Moberg PJ, Wilkinson JR, Hurtig HI, Stern MB, Weintraub D (2009). Montreal cognitive assessment performance in patients with Parkinson's disease with "normal" global cognition according to mini-mental state examination score. Journal of the American Geriatrics Society 57, 304-308.

Pasotti C, Zangaglia R, Sinforiani E, Minafra B, Bertaina I, Pacchetti C (2012). Cognitive function in Parkinson's disease: the influence of gender. Basal Ganglia 3, 131-135.
Petersen RC (2004). Mild cognitive impairment as a diagnostic entity. Journal of Internal Medicine 256, 183-194.

Picillo M, Barone P, Amboni M, Moccia M, Pellecchia MT (2014). Comment on Szewczyk-Krolikowski et al.: the influence of age and gender on motor and non-motor features of early Parkinson's disease: initial findings from the Oxford Parkinson Disease Center (OPDC) discovery cohort. Parkinsonism and Related Disorders 20, 1319-1320.

Pusswald G, Lehrner J, Hagmann M, Dal-Bianco P, Benke T, Marksteiner J, Mosbacher J, Ransmayr G, Sanin G, Schmidt R (2015). Gender-specific differences in cognitive profiles of patients with Alzheimer's disease: results of the Prospective Dementia Registry Austria (PRODEM-Austria). Journal of Alzheimer's Disease: JAD 46, 631-637.

Quade D (1967). Rank analysis of covariance. Journal of the American Statistical Association 62, 1187-1200.

Riedel O, Heuser I, Klotsche J, Dodel R, Wittchen HU (2010). Occurrence risk and structure of depression in Parkinson disease with and without dementia: results from the GEPAD Study. Journal of Geriatric Psychiatry and Neurology 23, 27-34.

Riedel O, Klotsche J, Spottke A, Deuschl G, Forstl H, Henn F, Heuser I, Oertel W, Reichmann H, Riederer $P$, Trenkwalder C, Dodel R, Wittchen HU (2008). Cognitive impairment in 873 patients with idiopathic Parkinson's disease. Results from the German Study on Epidemiology of Parkinson's Disease with Dementia (GEPAD). Journal of Neurology 255, 255-264.

Schendan HE, Amick MM, Cronin-Golomb A (2009). Role of a lateralized parietal-basal ganglia circuit in hierarchical pattern perception: evidence from Parkinson's disease. Behavioral Neuroscience 123, 125-136.

Schretlen D (1997). Brief Test of Attention (BTA). Psychological Assessment Resources: Florida.

Scott B, Borgman A, Engler H, Johnels B, Aquilonius SM (2000). Gender differences in Parkinson's disease symptom profile. Acta Neurologica Scandinavica 102, 37-43.

Sherwin BB (2012). Estrogen and cognitive functioning in women: lessons we have learned. Behavioral Neuroscience 126, 123-127.

Stern Y (2009). Cognitive reserve. Neuropsychologia 47, 20152028.

Sturm W, Willmes K, Horn W (1993). Leistungsprüfsystem für 50-90jährige (LPS 50+). Hogrefe: Göttingen.

Szewczyk-Krolikowski K, Tomlinson P, Nithi K, Wade-Martins R, Talbot K, Ben-Shlomo Y, Hu MT (2014). The influence of age and gender on motor and non-motor features of early Parkinson's disease: initial findings from the Oxford Parkinson Disease Center (OPDC) discovery cohort. Parkinsonism and Related Disorders 20, 99-105.

Taylor KS, Cook JA, Counsell CE (2007). Heterogeneity in male to female risk for Parkinson's disease. Journal of Neurology, Neurosurgery and Psychiatry 78, 905-906.

Tombaugh TN (2004). Trail Making Test A and B: normative data stratified by age and education. Archives of Clinical Neuropsychology 19, 203-214.

Tomlinson CL, Stowe R, Patel S, Rick C, Gray R, Clarke CE (2010). Systematic review of Levadopa dose equivalency 
reporting in Parkinson's disease. Movement Disorders 25, 2649-2685.

Twelves D, Perkins KS, Counsell C (2003). Systematic review of incidence studies of Parkinson's disease. Movement Disorders 18, 19-31.

Uc EY, McDermott MP, Marder KS, Anderson SW, Litvan I, Como PG, Auinger P, Chou KL, Growdon JC (2009). Incidence of and risk factors for cognitive impairment in an early Parkinson disease clinical trial cohort. Neurology 73, 1469-1477.

Valenzuela MJ, Sachdev P, Wen W, Chen X, Brodaty H (2008). Lifespan mental activity predicts diminished rate of hippocampal atrophy. PLoS ONE 3, e2598.

Van Den Eeden SK, Tanner CM, Bernstein AL, Fross RD, Leimpeter A, Bloch DA, Nelson LM (2003). Incidence of Parkinson's disease: variation by age, gender, and race/ ethnicity. American Journal of Epidemiology 157, 1015-1022. van Hooren SA, Valentijn AM, Bosma H, Ponds RW, van Boxtel MP, Jolles J (2007). Cognitive functioning in healthy older adults aged 64-81: a cohort study into the effects of age, sex, and education. Neuropsychology, development, and cognition. Section B, Aging, neuropsychology and cognition 14, 40-54. van Rooden SM, Colas F, Martinez-Martin P, Visser M, Verbaan D, Marinus J, Chaudhuri RK, Kok JN, van Hilten JJ (2011). Clinical subtypes of Parkinson's disease. Movement Disorders 26, 51-58.

Weiss E, Siedentopf CM, Hofer A, Deisenhammer EA, Hoptman MJ, Kremser C, Golaszewski S, Felber S, Fleischhacker WW, Delazer M (2003). Sex differences in brain activation pattern during a visuospatial cognitive task: a functional magnetic resonance imaging study in healthy volunteers. Neuroscience Letters 344, 169-172.

Welch LW, Doineau D, Johnson S, King D (1996). Educational and gender normative data for the Boston Naming Test in a group of older adults. Brain and Language 53, 260-266.

World Medical Association Declaration of Helsinki (1997). Recommendations guiding physicians in biomedical research involving human subjects. Journal of the American Medical Association 277, 925-926.

Zec RF, Burkett NR, Markwell SJ, Larsen DL (2007). A cross-sectional study of the effects of age, education, and gender on the Boston Naming Test. The Clinical Neuropsychologist 21, 587-616. 